\title{
Intrauterine Intussusception in Etiology of Jejunal Atresia
}

\author{
Amulya K. Saxena ${ }^{\mathrm{a}}$ Cornelia van Tuil ${ }^{\mathrm{b}}$

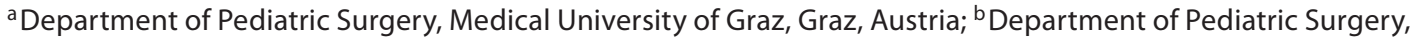 \\ University of Heidelberg, Heidelberg, Germany
}

A term male newborn presented with abdominal distention $12 \mathrm{~h}$ after birth. The infant had passed meconium twice; however, during this time he had an episode of bilious vomiting. Ultrasound examination was performed and dilatation of the proximal small intestine along with obstruction was observed. The newborn was prepared and an explorative minilaparotomy was performed.

The site of obstruction was located in the proximal jejunum approximately $20 \mathrm{~cm}$ distal from the ligament of Treitz. At the point of obstruction, the proximal end of the jejunum terminated into a blind sac (type-1 atresia); however, a 12-cm long 'tumor' occluded the lumen of the jeju- num caudally and could be palpated distal to the obstruction. The lumen of the jejunum $1 \mathrm{~cm}$ distal to the obstruction was incised and the 'tumor' was identified to be a necrotic intussusception (fig. 1). The section of the involved jejunum was resected and an end-to-end anastomosis was performed. The postoperative course was uneventful.

The long intrauterine jejunal intussusception was responsible for the mesenterial incarceration leading to the necrosis of the intussuscepted intestinal segment (fig. 2). The herniation of the mesenterium and the resulting vascular insult is presumed to be the etiology for the jejunal atresia.

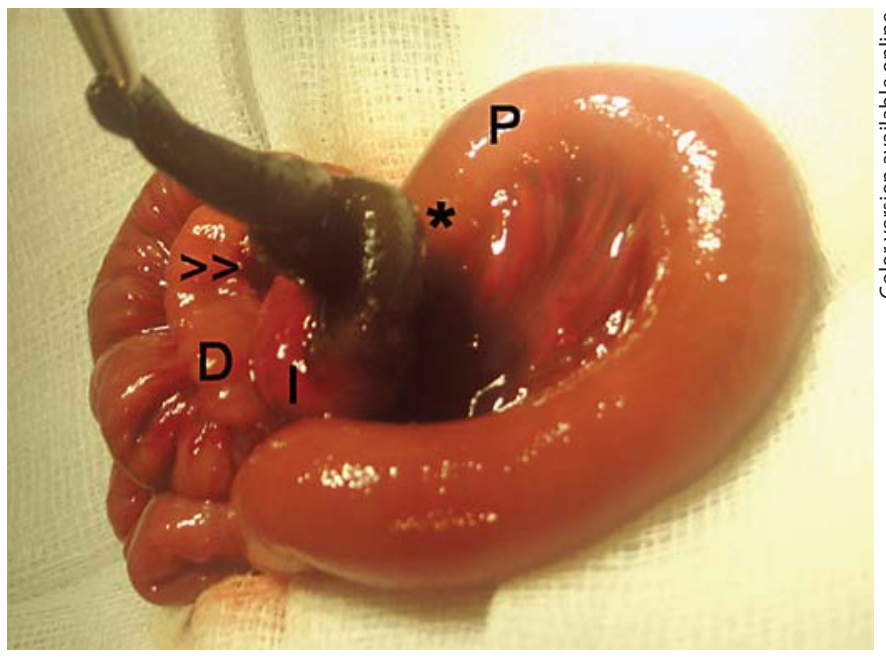

Fig. 1. Intraoperative view of the bowel showing the dilated proximal jejunum $(\mathrm{P})$ and localization of the atresia $(*)$. Distal to the atresia (D) the jejunum lumen was incised (arrows) from which a necrotic $12-\mathrm{cm}$ intussusception (I) could be removed from the lumen.
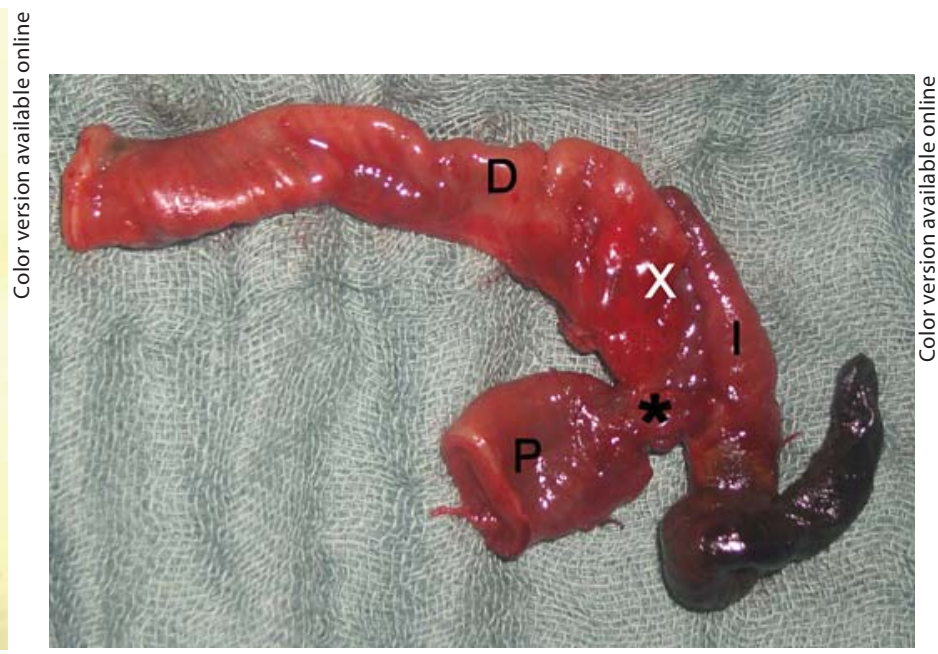

Fig. 2. View of the resected colon showing the proximal colon $(\mathrm{P})$ and localization of the atresia $\left(^{*}\right)$. The incision on the jejunum (X) distal to the atresia is shown where the intussusception (I) was retracted out of the distal bowel loop (D).

\section{KARGER}

Fax +41613061234 E-Mail karger@karger.ch www.karger.com

\author{
(C) 2008 S. Karger AG, Base \\ 0253-4886/08/0253-0187\$24.50/0 \\ Accessible online at: \\ www.karger.com/dsu
}

Amulya K. Saxena, MD

Department of Pediatric Surgery, Medical University of Graz

Auenbruggerplatz 34, AT-8036 Graz (Austria)

Tel. +43 316385 3762, Fax +433163853775

E-Mail amulya.saxena@meduni-graz.at 